\title{
Female Under-Representation in Computing Education and Industry - A Survey of Issues and Interventions
}

\author{
Joseph Osunde, Gill Windall, Professor Liz Bacon and Professor Lachlan Mackinnon \\ Department of Computing and Mathematical Sciences, \\ University of Greenwich, London, UK
}

\begin{abstract}
This survey paper examines the issue of female under-representation in computing education and industry, which has been shown from empirical studies to be a problem for over two decades. While various measures and intervention strategies have been implemented to increase the interest of girls in computing education and industry, the level of success has been discouraging.

The primary contribution of this paper is to provide an analysis of the extensive research work in this area. It outlines the progressive decline in female representation in computing education. It also presents the key arguments that attempt to explain the decline and intervention strategies. We conclude that there is a need to further explore strategies that will encourage young female learners to interact more with computer educational games.
\end{abstract}

Keywords-Female under-representation; Structural factors; Biological factors; Socio-cultural factors; User Interaction

\section{INTRODUCTION}

Female under-representation in computing education and industry is a well-known issue. A colossal amount of literature exists on this topical issue and solutions have been proposed to solve this problem. A number of these proposals have been implemented over the years in an attempt to address this problem.

This paper focuses on the under-representation of females in computing education and industry. It does not include related subjects and careers such as Information Technology and Science. Denning et al. [20] define the discipline of computing as "the systematic study of algorithmic processes that describe and transform information: their theory, analysis, design, efficiency, implementation and application". The discipline fundamentally investigates systems and how they can be automated. This discipline includes professions in artificial intelligence, computer engineering, human-computer interaction, robotics etc. Information technology is the convergence of computing, information content and telecommunications. The term "computing education and industry" in this paper refers to computer science as a subject and computer science careers.

The first section of this paper presents the evidence of the problem in education and industry including a comparison of trends in other Science, Technology, Engineering and
Mathematics (STEM) subjects. The second section reviews the key factors which have been proffered as potential causes for the under-representation of females in computing education and industry. This section will further review the key arguments and associated theories.

The key intervention strategies implemented which have been employed in an attempt to reverse this trend are discussed in the third section of the article. A review of these strategies provides an opportunity to explore the breadth of current solutions and identify areas for further investigation.

\section{EVIDENCE OF THE PROBLEM}

\section{A. Computing Education and Industry}

The evidence of the problem will be reviewed from both the education and industry perspective. This will provide a contextual insight into the nature of the problem. An analysis of research work on the participation rates of females in computing education and careers indicate that the level is low in many parts of the world [33], [72]. This trend has a history dating back to the early 1980 s. Prior to this time there was a healthy level of female representation in both computing education and industry. In 1960, 65\% of computer programmers in the United States of America (USA) were women and historically women have been highly influential in the field of computing [36].

Empirical studies have shown that the numbers of females in computer science education and careers decrease progressively from the early stages of secondary education until later stages of education [21], [57]. The key factors that have been forwarded as potential explanations for this trend will be explored further in this paper. The progressive decline of females in computing education from secondary education stage leading to tertiary education is described by Gurer and Camp as "the pipeline shrinkage problem" [36]. This pipeline effect has been identified as a worldwide issue as data collected from many parts of the world presents a broadly similar picture although there are some exceptions in countries such as Malaysia, Singapore and Thailand, where the female representation in computing education is $50 \%$ and above [33].

In the United Kingdom (UK) statistics from the Higher Education Statistics Agency, indicates that the proportion of female computer science undergraduates was $18 \%$ as at 2011 [40]. This percentage has reduced significantly from $28 \%$ in 
1990 as indicated by [78]. This demonstrates the progressive decline in the representation of females in computing education over the years.

A similar picture is presented in the USA in a related study by [72], where it was shown that the share of bachelors' degrees awarded in the USA to females in the past two decades increased in almost all major science and engineering fields except in computing. Historically, science and engineering has suffered from female under-representation and specific measures have been implemented to reduce the effect.

In another extensive study of the participation level of females in computing education by Galpin, it was shown that this trend pervades Western Europe, Southern Europe, Scandinavia and Africa [33]. Galpin summarized the findings in 36 countries at tertiary education level as "generally, participation is low - most countries fall in the 10-40\% range with a few below $10 \%$ and a few above $40 \%$ ".

The under-representation of females in computing education contrasts with the level of their representation and achievement in other subject areas as shown by the European Key Data on Education in 2009. It clearly presents a trend of a generally higher level of female achievement in education. The number of women who gained upper secondary qualifications was greater than the corresponding number of men in all European countries, the only exception being Turkey.

Furthermore, empirical data on all countries of the EU-27 shows that $60 \%$ of tertiary education graduates are women. In some member states (Estonia, Latvia, Lithuania, Hungary and Portugal), the number of women undergraduates outnumber men by the ratio 2:1. During the period 2002-2006, there were approximately three women tertiary education graduates for every two men and this proportion was relatively stable in most member states [46]. A similar picture is presented by the UK Royal Society [66] and in the US where the number of female tertiary education graduates increased generally except in computing education; where there has been a consistent decrease in the awards of Bachelor's degrees from $18 \%$ in $1993 / 1994$ to $12 \%$ in $2006 / 2007$.

There is data to suggest that females that do participate in computer science, mathematics and computing related subjects such as information communications technology (ICT) outperform the males. In the UK, the achievement performance data from the Joint Council of Qualifications board between 2004 and 2011 indicates that females between the ages of 16 and 18 have consistently outperformed the males in ICT and Computing Science at both Advanced Level and General Certificate of Secondary Education (GCSE) qualification stages. Between 2001 and 2008, the females outperformed the males in GCSE Mathematics with the males outperforming the females between 2009 and 2011. For Advanced Level Mathematics, the females outperformed the males between 2001 and 2011 and in Additional Mathematics between 2003 and 2011[44]. Irrespective of this academic capability and higher attainment levels the percentage of females taking up computing at Advanced Level is on a progressive decline from $12 \%$ in 2004 to $8 \%$ in 2011 [28],[29].

Unsurprisingly, the decline in education correlates with the female under-representation in the computing industry in spite of the improving employment opportunities in this field. Employment statistics indicate increased employment opportunities in the industry. Lazowska [48] commented "among all occupations in all fields of science and engineering, computing occupations are projected to account for nearly $60 \%$ of all job growth between now and 2018 ". This projection of opportunities is also echoed by the UK department for Business Innovation and Skills. The department forecasts that the computing industry is set to grow at four times the rate of other professions [8]. However, The UK Resource Centre (UKRC) indicated that as at 2008, the representation of women in the computing industry was only $14.4 \%$ [70].

Computer science as a subject is a fundamental source of talent for the technology sector and it is equally of immense economic value [28]. The progressive drop-off in the uptake of computing degrees especially amongst females has been identified as a great concern for education and industry.

\section{B. Comparative trend with other STEM subjects and jobs}

Education and employment in the STEM subjects has been plagued by female under-representation for decades and the statistical evidence presents a grim picture of the situation. Over the years, the representation of females in STEM careers and subjects such as Mathematics, Physics, Chemistry, Computer Science and Technology has been poor. The USA Economic and Statistics Administration (ESA) indicated that $40 \%$ of men with STEM degrees work in STEM jobs compared to $26 \%$ of women. Consequently, the male workforce in STEM is more than twice the number of females, with a large number of female STEM graduates working in education or healthcare. Within the STEM jobs, computing and mathematics jobs account for close to $47 \%$ of all STEM employment. Women representation has varied over time across the STEM occupations, with the female share in computing and mathematics declining over the years as their share has risen in other STEM occupations [27]. A similar situation to that in the US exists in the UK, with only $13 \%$ of the STEM workforce being women between 2011 and 2012 [71].

Furthermore, a historical review of the trends in UK STEM education indicates that the percentage of females entered for STEM subjects at GCSE and Advanced Level was on the decline until 2011. Intervention strategies implemented with the aim of improving female representation include: the use of role models, development of gender specific content, improved teaching, use of real world scenarios in learning exercises and addressing misconceptions [37]. In recent years there have been improvements in the numbers of females engaging with almost all STEM subjects. The percentage of girls entered for Physics and Chemistry GCSE increased by $82 \%$ and $79 \%$ respectively between 2009 and 2012.

Furthermore, Advanced Level Chemistry and Physics rose in 2012 by $13 \%$ compared to 2009. A comparative trend in 
Mathematics also indicates that the numbers of females entered increased by $17 \%$ compared to 2009 . However, the number of entries for Advanced Level Computing has fallen progressively for ten years with the subject accounting for just $0.4 \%$ of all Advanced Level subjects. Only $6.5 \%$ of entrants were females in 2013, which is $1.3 \%$ points lower than 2012 [29].

In higher education there was an increase of $21 \%$ in the number of females obtaining Engineering and Technology degrees between 2008 and 2011. A similar increase of $27 \%$ in Mathematical Sciences was shown in the same period. In contrast, a progressively decreasing number of females in Computer Science are shown for higher education [71]. There is a progressive decline in the numbers of females engaging with Computer Science at degree level. Statistics published in two reports by the Higher Education Statistics Authority (UK) indicate that between 2004 and 2011 female undergraduates studying computing decreased from $24 \%$ to $18 \%$ [39], [40].

\section{Possible CAUSES OF Female UndeR- REPRESENTATION IN COMPUTING}

A number of theories have been proposed to explain female under-representation in computing education and industry. The theories can fundamentally be divided into causes which are based on inherent or biological differences (essentialist theory) [31], social-cultural [26]; [67] and structural factors [2].

The essentialist theories in relation to imbalance of gender representation in computer science are founded on the view that the disparity is caused by inherent differences between males and females such as mathematical competence and computational thinking ability. According to Strevens [65] this assumption based on differences in natural ability means that males will dominate computing education and industry as they are naturally more suited to it than females. This would further suggest that intervention strategies will not lead to an improvement in female representation in computing due to inherent factors which favour males and disadvantage females.

In contrast, the socio-cultural viewpoint holds that the differences are caused by external (e.g. stereotyping) and internal (e.g. self-expectation) factors which influence the development of males and females [26]; [67]. These factors originate from societal and cultural perceptions. They translate into accepted "norms" and "beliefs" in our society leading to low confidence levels and poor motivation of females to engage with the subject and consequently the industry.

Closely linked to socio-cultural factors are the structural factors which translate into the nature of institutions (home, education and industry) such that they limit opportunities for certain groups to increase in representation without structured intervention [2].

In the educational environment, the uninspiring nature of the Information Technology and Communications (ICT) curriculum has often been identified as a structural constraint decreasing the interest in computers and computer science especially amongst females [3], [69]. Furthermore, it is suggested that a lack of inspirational and skilled teachers to deliver the computer science curriculum is another factor that has a negative impact on engagement with computer science in primary and secondary education levels [69].

Structural constraints can be found in: home and family life, the learning environment, computer attitudes and anxiety, lack of role models, perception of computer science and educational computer software [1]. Combinations of both socio-cultural and structural factors have been shown to consequently affect career choice, career persistence and advancement in computing [2].

An exposition of these key factors will be explored further in order to grasp the complexity of the nature of these viewpoints.

\section{A. Inherent gender characteristics linked to computer science capability}

This argument postulates that there are a number of inherent gender characteristics that influence the decision to study computer science and subsequently engage in the workforce. This essentialist argument promotes the view that there is a male superiority in arithmetical computation, reasoning and spatial cognition [34]. Baron-Cohen [4] further indicated that an underpinning viewpoint in support of this argument is the empathizing-systemizing (E-S) theory. This theory hypothesizes that the female brain is predominantly wired for empathy and the male brain wired for building systems. On this premise, males are naturally drawn to subjects and careers that are linked with problem solving through designing and building of systems such as engineering and computing. Similarly, females are drawn towards subjects and careers such as health care and socially demanding environments.

The concept of computing as an area of study emerged from the principles of traditional mathematics. Initial emphasis was on numerical computation, then numerical analysis [73], [75] and then symbolic computation [53].

Consequently Computer Science could be referred to as a branch of applied mathematics relying heavily on abstraction. Although there is no study to support the hypothesis that computing professionals and students are proficient in mathematics, studies have however shown that mathematics is an important tool for problem solving and conceptual understanding of computing [11], [32]. Wing [77] defines computational thinking as "a problem solving approach concerned with conceptualization, developing abstractions and designing systems (automations)".This element of problem solving as a key requirement for computer science correlates with skills required in mathematics, designing systems and spatial ability. On this basis, the Essentialists and E-S theorists would argue that this accounts for the lack of females in computing education and industry.

\section{B. Socio-cultural factors}

Studies into factors that determine success in computing indicate that self-efficacy and intrinsic motivation, which are socially constructed, are key factors as opposed to the innate intelligence or ability of the students. This argument provides strong evidence that innate human qualities (or intelligence) 
are not a pre-requisite for success in computing education [7]. Also a growing body of research challenges the inherent characteristics arguments linked to gender differences on the basis that the differences are socially constructed [26], [31]. Empirical studies carried out to determine the effect of sex differences on mathematical ability and spatial visualization indicate that there are no significant gender differences in performance [50], [52].

Furthermore, the socio-cultural argument suggests that the differences with computer science linked abilities are socially engineered as there are no identified cognitive variations. However there are significant differences in self-confidence. This is higher in the boys as they believe that mathematics and computing is an exclusive domain for males [50], [52].

1) Confidence and motivation: There are significant differences in self-confidence exhibited by males and females in the computing environment. Studies suggest that females exhibit low self-confidence in the computing environment comparative to the males who are very confident [22],[61]. In an academic setting females often become more motivated by striving for favorable judgments from colleagues of their competence as opposed to actually enhancing their competence. This is based on a common understanding between the genders that mathematics and computing are male domains [23], [68].

The psychological effects of both biological and socially engineered gender differences [31] create a stereotypic environment in both work and education. This consequently impacts female confidence and motivation to study the subject and career access. Behm-Morawitz and Mastro [6] further indicate that these stereotypic beliefs tend to be presented in popular media, thereby subconsciously affecting social perception of gender differences thus leading to implicit bias in computing education and workforce.

2) Perception of the Computer Scientist: Makoff [51] indicates that society has a profound impact on young girls' image of themselves in relation to computer science. Makoff argued that most of the images of computer scientist are negative and imply that computing is for "Nerds" or men only. A similar study of eighth grade pupils' (13-14 years old) expectations of what a knowledgeable computer user would look like by [55] illustrated that the majority expect a male user with glasses. However, the picture created by the sixth grade pupils (11-12 years old) presented less stereotypic characteristics and a reasonable number of female representations. This emphasises the increasing impact of socially engineered gender differences with age. This genderspecific view of computer science begins to develop from early stages of secondary education and becomes entrenched towards the end of secondary education [21].

\section{Structural factors}

Structural factors have been shown from empirical studies to impact on education and career access, choice and advancement [9]. The key structural factors include:
1) Home and family life: In academia and industry, men and women face challenges in pursuing demanding careers like computing while meeting family responsibilities. However, research indicates that women and men are affected differently by the "family penalty" [62]. Women tend to forego marriage or children and may delay having children in order to pursue demanding careers such as computing [41]. Although marriage does not appear to impact on a career in computing, having children in the home may affect work related productivity due to the fact that traditionally women are the primary care givers in the home setting [63].

2) The learning environment (classroom and virtual): The computer science learning environment has been referred to as being "Hostile" [76] and "Nerdy" [55]. Research literature on the computer science learning environment has also indicated that there is a cultural difference in the values of men and women. It has been argued that women are motivated by tasks and careers that encourage social interactions which directly contribute to society. Males have been shown to be less motivated by these values [24]. On this basis, a learning environment that does not encourage social interaction, or where the skills being learnt do not clearly contribute to society, will appeal less to females.

3) Attitudes towards computers and computer anxiety: Chen [17] and Durndell and Haag [22] reported that men held more positive attitudes towards computers and had lower computer anxiety than women. In a study on computerpobia (computer anxiety, computer attitudes and computer cognitions/ feelings) with a focus on male and female learners in 1987, Rosen, Sears and Weil [60] indicated that there is no difference in gender with regards to computer anxiety. However, there was a significant gender issue with regard to attitudes towards computers, with females having more negative attitudes. This was supported by Levin and Gordon [49] and Shashaani and Khalili [61], suggesting that boys have significantly more positive attitudes towards computers than girls.

According to Busch [12], the process of socialization provides an explanation for the gender differences in attitudes towards computers. Busch argued that sex-role identity is formed initially within the family where norms are internalized, attitudes learned and self-image acquired. These behaviors are later reinforced or shaped in school and work settings where society's basic culture is transmitted on to its inhabitants. Consequently, according to [12], gender differences in attitudes towards computers may be a reflection of social experiences.

\section{INTERVENTION STRATEGIES AND INITIATIVES}

A number of strategies and interventions have been explored to address the issue of female under-representation in computing education and industry. The solution(s) applied in any given instance depend on the nature of the problem identified [33]. The key intervention strategies that have been implemented will be further reviewed. 


\section{A. Gender grouping, collaborative working, role models and mentoring}

A study carried out by [21] indicates that: gender grouping, role models/mentors, school curriculum and organization policies are important socio-cultural determinants for motivating females into computing. In a review of the importance of mentoring in higher education [41] stated that "it helps address the feelings of isolation and marginalization". Inkpen, Booth, Klawe and Upitis [43] showed that gender grouping improved performance and attitudes in the computing education environment more significantly in females than males. Other studies [13] and [74] have indicated that the implementation of pairprogramming is beneficial for all computer science students, especially female students at post-secondary levels. Werner, Hanks and McDowell [74] further demonstrated that it particularly improves the confidence of females and consequently reduces attrition levels.

\section{B. Working parties and initiatives}

As a result of the disproportionately low numbers of women in computing education and the workforce, working parties and initiatives have been instigated to improve the awareness of this problem and provide various support measures for females. In the USA, a number of initiatives (Women in Computing Committee, The Kindergarten to $12^{\text {th }}$ Grade, MentorNet etc.) have been set up to encourage women into computing at both pre-tertiary and tertiary education levels. These groups also seek to ensure that role models are provided, computing career myths are dispelled and accurate information is provided to key influencers of girls [47]. In the UK many groups have been inaugurated with the aim of recruiting and retaining girls and women in IT. The BCS (Chartered Institute for IT) Women is an example of such a group. The Computer Club for Girls (CC4G) which encourages girls between ages 10 - 14 to engage with IT and take up the study of the subject at a higher level is another example [16].

\section{Educational policies}

A number of research studies have supported the review of educational policies and structure in order to improve the accessibility of computer science study. In the UK, computer science has been introduced in the national curriculum and will be mandatory for delivery in 2014 at Key Stage 2-Key Stage 4 - age 11-16 [69], [14]. It is hoped that this will improve the female representation in computing education and subsequently the computing industry due to improved accessibility of the subject from an early age. Furthermore, in the UK there is a proactive measure to develop teaching excellence in computing for new and existing teachers. This strategy aims to ensure that confident and effective professionals can further advance the course of motivating learners to engage with the subject [10].

\section{Educational games as a motivating tool and its implications}

Games have become an integral part of our social and cultural environment and have a particular appeal to both children and adolescents [56]. Research shows that the intrinsic motivation demonstrated towards games provides the opportunity for their use as a learning tool [54], [45]. This has been combined effectively with academic content to create "Digital Game-Based Learning" [59]. This has been used extensively in computer science education for both instructional content and skills acquisition aspects of the subject. The use of games in this context is due to the "game cycle" effect which should encourage players or learners to return to the gaming environment due to the immersive and engaging experience [35].

The numbers of females playing entertainment games are on the increase with a good number becoming ardent gamers relative to the males [27], [79]. However, this increase has not been replicated with educational games. Some researchers have linked this to the presence of gender stereotypic scripts embedded in educational games [38], [42].

Empirical studies on the use of games for educational purposes indicate that boys develop greater familiarity, confidence and ability due to the gender stereotypic scripts which tend to present the computer learning environment as a male domain [15], [58]. Research indicates that stereotypic scripts found in educational software result in more girls and women suffering from computer anxiety in comparison to men or boys [42]. A reaction against this has been the development and use of gender neutral software which explores the reduction or removal of "male type" representations from the software design.

These "male type" representations include software features such as: violence, competition, explosions, war scenes etc. Gender neutral software has been shown to provide girls and women with better opportunities to explore systems and arrive at solutions [18]. However, there are arguments about the most appropriate representations of gender neutral elements as the use of non-gendered characters such as cute animals could be considered condescending and unrealistic by both genders [30].

In contrast to the use of gender-neutral software, genderspecific software is software where different versions are created for boys and girls. Some studies suggest that genderspecific software is often based on gender stereotypes leading to undesirable outcomes for both genders [6]. A typical example of an undesirable and possibly stereotypic representation includes the exaggeration of feminine features, gender-linked roles and goal oriented learning models which have been identified to reduce self-efficacy and development of competence [23]. According to [5], high self-efficacy is critical in problem solving because it influences the use of cognitive strategies. Considering that computer science educational materials are predominantly software-based, the proliferation of stereotypic scripts and their effects are far reaching to learners of all ages.

\section{Discussion, CONCLUSION AND Future DiRECTION}

This survey paper has analyzed the literature on the underrepresentation of females in computing education and industry. A comparative review of the STEM subjects indicates that increases in representation for all other subjects have occurred in recent years with the exception of computer 
science at both secondary and higher educational levels. A comparative analysis of female performance educationally was reviewed to identify if there is a correlation with the computer science trend. The statistical data and literature indicated good achievement levels of females relative to the males. This further prompted a review of the causes of underrepresentation of females in computing education and industry.

The literature suggests that there are arguments for all three factors (biological differences, social - cultural and structural) as possible causes for under-representation of females in computing education and industry. Although there is scientific evidence to support biological differences in compositions of male and female organs such as the brain, there is no experimental evidence to support the essence of superiority [65]. The under-representation of females in computing education and industry appears to be influenced by socio-cultural and structural factors. There are empirical data on achievement and historical contributions of females to computer science which supports this conclusion. It suggests that the influences of socio-cultural and structural factors contribute to the current under-representation of females in computing education and industry.

The perception of gender and gender-linked social values is progressively disseminated in our society and all forms of media including educational media and resources. These gendered values are widely accepted in society as a norm, thereby having a tremendous impact on self-efficacy and cognitive resilience of the under-represented population. This position inhibits learners especially in computer science as self-efficacy and cognitive strategies have been shown to be vital for success in problem-solving subjects and careers.

Furthermore, structural factors which have been identified to exist in various institutions such as the home, educational environment and the workplace have immense effect on educational and career choices. This has been shown to create a barrier in young learners accessing subjects such as computing and leading to elevated attrition levels in higher education. The effect of structural factors has further reduced advancement options in careers linked to computing for females.

The solutions reviewed based on the literature have been implemented by various groups and policy makers. Given the history and the multiple approaches which have been taken, there has been little effect in the overall representation of females in computing education and industry. Hence the position continues to decline. It is unclear that a single solution will solve the problem, making it imperative to further explore a range of possible solutions.

There is a continuous drive to ensure that educational policies and structure is more inclusive for both genders. Furthermore, the introduction of computer science early on in the school curriculum would benefit both genders and help dispel gender-role identity in computing education. Other intervention strategies such as mentoring programmes, awareness campaigns and initiatives should further encourage more females to engage with the subject and consequently the occupations within the discipline.
Gender-role identity has been identified as being embedded in educational resources such as books, educational media and software.

There is need for further investigation of the role of educational computer games in the under-representation of females in computing education and industry. Unresolved issues include limitations of gendered software such as stereotypic scripts with and the dilemma with the representation of gender neutral features in non-gendered software. Furthermore, whilst games have shown themselves to be educationally effective tools, their use as currently designed has not had a positive impact on the interest shown by females in the subject of computing. The question 'how can the learner interaction with educational games be used to inspire more females to study the discipline of computing?' is clearly a key question worthy of further investigation.

Our future work will investigate how young learners of age 11-14 interact with digital games and the game features that are significant and appealing to this age group. The information collected will be used to design prototype educational computer games that will be tested and used to inform the creation of a framework for the design of educational computer games.

\section{ACKNOWLEDGMENT}

The authors would like to particularly thank Professor Cornelia Boldyreff also of the University of Greenwich, London for her support and contribution to this survey paper.

\section{REFERENCES}

[1] M. Adya and K. M. Kaiser, "Early determinants of women in the IT workforce: a model of girls' career choices," Information Technology \& People, 18(3), 230-259,2005.

[2] M. K.Ahuja, "Women in the information technology profession: a literature review, synthesis and research agenda," European Journal of Information Systems, 11(1), 20-34, 2002.

[3] N. Anderson, C. Lankshear, C. Timms and L. Courtney, 'Because it's boring, irrelevant and I don't like computers': "Why high school girls avoid professionally-oriented ICT subjects," Computers \& Education, 50(4), 1304-1318, 2008.

[4] S. Baron-Cohen, "The essential difference: Men, women and the extreme male brain," Penguin, 2004.

[5] L. Beckwith, M. Burnett, S. Wiedenbeck and V. Grigoreanu, 'Gender HCI: What About the Software?' .IEEE Computer Society, 39(11), 97101, 2006.

[6] E. Behm-Morawitz and D. Mastro, "The effects of sexualisation of female game characters on gender stereotyping and female selfconcept," Sex Roles, 61(11-12), 808-823, 2009.

[7] F. Belanger, T. Lewis, G.M. Kasper, W.J. Smith and K.V. Harrington, 'Are Computing Students Different? An Analysis of Coping Strategies and Emotional Intelligence,' IEEE Education Society, 50 (3), 188-196, 2007.

[8] Business Innovation and Skills. New Industry New Jobs, Skills System Case Studies, March 2010

[9] T.C. Blum, D.L. Fields and J.S. Goodman, "Organization-level determinants of women in management," Academy of Management Journal, 37(2), 241-268,1994.

[10] British Computer Society. Teaching Scholarships, 2014.

[11] A. Bundy, "The Computer Modelling of Mathematical Reasoning", Tobias Edler von Koch, 2010.

[12] T. Busch, "Gender differences in self-efficacy and attitudes toward computers," Journal of educational computing research, 12(2), 147158,1995 . 
[13] J.C. Carver, L. Henderson, L. He, J. Hodges and D. Reese, "Increased retention of early computer science and software engineering students using pair programming," $20^{\text {th }}$ Conference on Software Engineering Education \& Training, IEEE, 2007.

[14] Computing At School " ICT and Computer Science in UK schools", 2012.

[15] J. Cassell and H. Jenkins (eds), "From barbie to mortal kombat," Gender and computer games, Cambridge, MA, MIT Press, 1998.

[16] Computer Club 4 Girls.About CC4G, 2013.

[17] M. Chen, "Gender and computers: The beneficial effects of experience on attitudes," Journal of Educational Computing Research, 2(3), 265282, 1986.

[18] J. Cooper and K.D. Weaver, Gender and Computers: Understanding the Digital Divide, Mahwah NJ, Erlbaum, 2003.

[19] W. Cukier, D. Shortt and I. Devine, "Gender and information technology: implications of definitions," ACM SIGCSE Bulletin, 34(4), 142-148, 2002.

[20] P.J. Denning et al., "Computing as a discipline," Computer, 22(2), 6370, 1989.

[21] H. Dryburgh, "Underrepresentation of girls and women in computer science: classification of 1990s research," Journal of Educational Computing Research, 23 (2), 181, 2000.

[22] A. Durndell and Z Haag, "Computer self-efficacy, computer anxiety, attitudes towards the Internet and reported experience with the Internet, by gender, in an East European sample. Computers in human behavior, 18(5), 521-535, 2002.

[23] C. Dweck, Mindsets and math/science achievement. Carnegie Institute for Advanced Study, Commission on Mathematics and Science Education, 2008.

[24] J.S. Eccles, 'Understanding Women's Educational and Occupational Choices', Psychology of Women Quarterly, 18(4), 585-609, 2006.

[25] Economic and Statistics Administration, "Women in STEM: A Gender Gap to Innovation", 2011.

[26] C. F. Epstein, "The Multiple Realities of Sameness and Difference: Ideology and Practice," Journal of Social Issues, 53(2), 259-277, 1997.

[27] Entertainment Software Association., "Essential Facts about the computer and the video game industry", 2012.

[28] E-Skills UK, "Creating The IT Nation - e-skills Uk issues strategic plans for 2009-2014", 2009.

[29] E-Skills UK, "GCSE, A Level students continue to overlook computing", 2013.

[30] D. Ferguson-Pabst, K. Persichitte, L. Loha and B. Pearman, "An analysis of the influence of gender, grade level and teacher on the selection of mathematics software by intermediate students," Information Technology in Childhood Education Annual, 2003(1), 5-27, 2003.

[31] C. Fine, "Explaining, or Sustaining, the Status Quo? The Potentially Self-Fulfilling Effects of 'Hardwired' Accounts of Sex Differences," Neuroethics 5(3),285-294, 2012.

[32] G. E. Forsythe, "A University's Educational Program in Computer Science," Communications of the ACM 10(1) , 3-11, 1967.

[33] V. Galpin, "Women in computing around the world," SIGCSE Bulletin, 34 (2), 94, 2002.

[34] D.C. Geary, S. J. Saults, F. Liu and M.K. Hoard, "Sex differences in spatial cognition, computational fluency and arithmetical reasoning," Journal of Experimental Child Psychology,77(4), 337-353, 2000.

[35] J.P. Gee, "Good Video Games Plus Good Learning," (Vol. 27). Peter Lang, 2007.

[36] D. Gurer and T. Camp, "An ACM-W Literature Review on Women in Computing,"SIGCSE Bulletin, 34(2), 121-127, 2002.

[37] K. Hayden , Y. Ouyang, L. Scinski, B. Olszewski and T. Bielefeldt, "Increasing student interest and attitudes in STEM: Professional development and activities to engage and inspire learners," Contemporary Issues in Technology and Teacher Education, 11(1), 47-69, 2011.

[38] L. Heemskerk, M. Volman, W. Admiraal and G. Ten Dam, "Gender inclusiveness in educational technology and learning experiences of girls' and boys," Journal of Research on Technology in Education (41), 253-276, 2009.

[39] Higher Education Statistics Authority, " Summary of UK performance indicators 2004/2005," 2006

[40] Higher Education Statistics Authority, "Student population,” 2012.

[41] C. Hill, C. Corbett and A.S. Rose, Why so Few? Women in Science, Technology, Engineering and Mathematics. AAUW. Washington, 2010.

[42] C. Huff, " Gender, software design, and occupational equity," ACM SIGCSE Bulletin, 34(2), 112-115, 2002.

[43] K. Inkpen, K.S. Booth, M. Klawe and R. Upitis, "Playing Together Beats Playing Apart, Especially for Girls," The first international conference on Computer support for collaborative learning. L. Erlbaum Associates Inc., 1995.

[44] Joint Council for Qualifications. A Levels examination results, 2014.

[45] Y.B. Kafai, "Playing and making games for learning," Games and Culture, 1(1), 36-40, 2006.

[46] Education, Audiovisual and Culture Executive Agency, “ Key Data on Education in Europe," Eurydice network, 2009.

[47] M. Klawe, T. Whitney and C. Simard, "Women in computing -Take 2," Communications of the ACM, 52 (2), 68-76, 2009.

[48] E. Lazowska, “where the jobs are..,"Computing community consortium blog, 2010.

[49] T. Levin and C. Gordon, "Effect of gender and computer experience on attitudes toward computers," Journal of Educational Computing Research, 5(1), 69-88, 1989.

[50] M.C. Linn, "Fostering equitable consequences from computer learning environments," Sex Roles, 13 (3), 229-240, 1985.

[51] J. Makoff, "Computing in America: a masculine mystique," New York Times, 1989.

[52] E. Mandinach and C.W. Fisher, "Individual differences and acquisition of computer programming skill," ACCCEL Report, Lawrence Hall of Science, University of California, 1985.

[53] J. McCarthy, Basis for a Mathematical Theory of Computation. In Computer Programming and Formal Systems, P. Braffort and D. Hirschberg (Eds.), North- Holland, Amsterdam, 1963.

[54] A. McFarlane, A. Sparrowhawk and Y. Heald, "Report on the educational use of games,"TEEM (Teachers evaluating educational multimedia), Cambridge, 2002.

[55] E.M. Mercier, B. Barron, and K.M. O'Connor, "Images of self and others as computer users: the role of gender and experience'. Journal of Computer Assisted Learning, 22 (5), 335-348, 2006.

[56] S. Mumtaz, "Children's enjoyment and perception of computer use in the home and the school," Computers and Education, 36 (4), 347-362, 2001.

[57] M. Papastergiou, "Are computer science and information technology still masculine fields? High school students' perceptions and career choices," Computers \& Education, 51(2), 594-608, 2008.

[58] M. Papastergiou, "Digital Game-Based Learning in high school Computer Science education: Impact on educational effectiveness and student motivation," Computer and Education, 52(1), 1-12, 2009.

[59] M. Prensky and M. Prensky, Digital game-based learning, 2008.

[60] L.D. Rosen, D.C. Sears and M.M. Weil, “Computerphobia,"Behavior Research Methods, Instruments, \& Computers, 19(2), 167-179, 1987.

[61] L.Shashaani and A. Khalili, "Gender and computers: Similarities and differences in Iranian college students' attitudes toward computers," Computers \& Education, 37(3), 363-375, 2001.

[62] C. Simard, A.D. Henderson, S.K. Gilmartin, L. Schiebinger and T. Whitney, Climbing the technical ladder: Obstacles and solutions for mid-level women in technology.Stanford, CA: Michelle R. Clayman Institute for Gender Research, Stanford University, \& Anita Borg Institute for Women and Technology, 2008.

[63] S. Stack, "Gender, children and research productivity," Research in Higher Education, 45 (8), 891-920, 2004.

[64] H. W. Stevenson and J. W. Stigler, The learning gap: Why our schools are failing and what we can learn from Japanese and Chinese education. Simon \& Schuster, New York, 1992. 
[65] M. Strevens, "The essentialist aspect of naïve theorie," Cognition, 74(2), 149-175, 2000.

[66] J. Vegso, "CRA Taulbee Trends: female students \& faculty." Computing Research Association 6, 2004.

[67] J. Teague, A structured review of reasons for the underrepresentation of women in computing. In Proceedings of the 2 nd Australasian conference on Computer science education (pp. 91-98). ACM, 1997.

[68] L. Temple and H.M. Lips, "Gender differences and similarities in attitudes toward computers," Computers in Human Behavior, 5(4), 215226, 1998.

[69] S, Furber, "Shut down or restart? The way forward for computing in UK schools." The Royal Society, London .2012.

[70] The UK Resource Centre, "Women in computing in the UK: A major shortage". 2010.

[71] UK Statistics, "Inspiring women as engineers, scientists and technical leaders," 2013.

[72] R.Varma, "Computing Self-efficacy among women in India," Journal of
Women and Minorities in Science and Engineering, 16(3), 257-274, 2010.

[73] J. Von Neumann and H. H. Goldstine, "Numerical inverting of metrics of high order," Bull. Amer. Math. Soc. 53(1947), 1021-1099, 1947.

[74] L.L. Werner, B. Hanks and C. McDowell, "Pair- programming helps female computer science students," ACM Journal of Educational Resources in Computing, 4,(1), 4, 2005.

[75] J.H. Wilkinson, The Algebraic Eigenvalue Problem. Clarendon Press, Oxford, 1965.

[76] B.C. Wilson, "A study of factors promoting success in computer science including gender differences," Computer Science Education, 12 (1-2), 141-164, 2002.

[77] M. Wing, "Computational thinking and thinking about computing," Philosophical Transactions of the Royal Society A: Mathematical, Physical and Engineering Sciences, 366, 3717-3725, 2008.

[78] R. Wright, Women in Computing: A cross-national analysis. Women in Computing. R. Lander and A. Adam. Exeter, Intellect Books,1997. N. Yee, "Social architectures in MMOs." The Daedalus Project (2008). 